\title{
Erosion Behavior of AISI 6061-T6
}

\author{
Juan Rodrigo Laguna-Camacho', Hermilo Martínez-García1, \\ Frumencio Escamilla-Rodríguez ${ }^{1}$, Carlos Alarcón-Rosas ${ }^{1}$, Celia María Calderón-Ramón1, \\ Lizeth Ríos-Velasco², Matilde Pelcastre-Lozano², Álvaro Casados-Sánchez', \\ Melesio González-Gómez ${ }^{1}$ \\ ${ }^{1}$ Faculty of Electrical and Mechanical Engineering, Universidad Veracruzana, Veracruz, Mexico \\ ${ }^{2}$ Facultad de Ciencias Químicas, Universidad Veracruzana, Poza Rica de Hidalgo, Veracruz, Mexico \\ Email: juanrodrigo.laguna@gmail.com
}

Received 2 March 2015; accepted 12 June 2015; published 15 June 2015

Copyright (C) 2015 by authors and Scientific Research Publishing Inc.

This work is licensed under the Creative Commons Attribution International License (CC BY). http://creativecommons.org/licenses/by/4.0/

(c) (i) Open Access

\begin{abstract}
In this work, erosion tests were performed to study the behavior of an aluminium alloy known as AISI 6061-T6 against the impact action of aluminium oxide abrasive particles. This material was selected because of its high ductility and tenacity. An erosion rig based on that in ASTM G76-95 was used to conduct the tests. The alumina particles had a particle size between 300 and $400 \mu \mathrm{m}$. Four incident angles, $30^{\circ}, 45^{\circ}, 60^{\circ}$ and $90^{\circ}$ were used to conduct the erosion tests. The particle velocity and the abrasive flow rate were $24 \pm 2 \mathrm{~m} / \mathrm{s}$ and $63 \pm 0.5 \mathrm{~g} / \mathrm{min}$. The room temperature was between $35^{\circ} \mathrm{C}$ and $40^{\circ} \mathrm{C}$. Chemical analysis of the material and abrasive particles were obtained using energy dispersive X-ray analysis (EDS). SEM images were employed to identify the wear mechanisms, which were characterized by high plastic deformation. The erosion rates were obtained and the results indicated that the maximum erosion damage was achieved at $30^{\circ}$ reducing progressively at normal incidence.
\end{abstract}

\section{Keywords}

Erosion, AISI 6061-T6, Aluminium Oxide, Wear Mechanisms

\section{Introduction}

Erosion is a wear process where the material removal is caused by the continuous impact of solid particles, a liquid and a combination of them on a surface. This wear process has been reported in several industrial components such as pipes [1], bends [2], control valves [3], steam turbine blades [4] and other mechanical elements. In relation to erosion studies on aluminum alloys, different investigations have been conducted. For instance, Christman [5] carried out erosion tests using ball bearings of $5 \mathrm{~mm}$ diameter on AISI 7075-T6 with different conditions and on AISI 
1100 , which is an annealed commercially pure aluminum. These materials were tested at low impact angles and normal incidence. The main emphasis in this work was material loss mode at normal impacts $\left(90^{\circ}\right)$. This led to a detailed study of the interaction of successive overlapping craters due to they found significant metal loss at normal incidence only when such overlap occurred. In almost all cases, the material removal was originated from the intersection of the craters. AISI 7075 alloy exhibited metal loss only at the intersection of craters, never in remote parts of the second crater. Overlapping craters on AISI 1100 material gave only splinters (lips or platelets) around the rim. In addition to this, it was observed that high strength AISI 7075-T6 was much less erosion resistant than soft ductile pure aluminum AISI 1100. This tendency was observed at low and high incident angles. The maximum erosion damage was observed at low impact angles, $20^{\circ}$ and $35^{\circ}$. Cousens \& Hutchings [6] presented detailed observations of the surface and subsurface features of aluminium alloys such as fully hardened 6061-T6, annealed 6061-0 and commercial purity aluminium 1100, eroded by glass beads at normal incidence. They proposed a new wear mechanism for erosive weight loss. A novel technique utilizing roll bonding to place marker layers underneath the specimen surface provided evidence of the pattern of flow of metal during erosion. Veerabhadra-Rao P. et al. [7] conducted a study of the morphology of the wear damage produced on two metals, an aluminium alloy (6061-T6511) and copper, by normal impact of spherical glass erodent particles. The results indicated that plastic deformation of the aluminium was characterized by radial tracks and concentric rings, these surface characteristics were identified in the craters formed by the direct impacts of the abrasive particles. The wear damage was more pronounced as the time was elapsed. Other significant factor was the pressure in the system, as it was increased, then the particle velocity was greater and more erosion was caused in the samples. In this research work, the main purpose was to study the erosion behavior of an aluminum alloy (AISI 6061-T6). The importance of this work is to know the wear modes of this aluminum alloy at different incident angles and determine the erosion rates under these particular conditions. Another significant aspect is to study the capacity of the aluminum oxide (angular shape) to deform the tested material. Erosion tests using an apparatus similar to that in ASTM G76-95 were conducted to establish the erosion rates at different incident angles, $30^{\circ}, 45^{\circ}, 60^{\circ}$ and $90^{\circ}$. In addition, the wear mechanisms were identified using SEM images.

\section{Experimental Details}

\subsection{Specimens}

The material used in the tests was AISI 6061-T6. This aluminum alloy is a medium to high strength heat-treatable alloy with a very good corrosion resistance and weldability. It has medium fatigue strength. T6 means solution heat treated and artificially aged. This alloy has applications in different industries such as helicopter rotor skins, tubing, truck frames, boilermaking and rivets. The alloy specimens were ground flat with 180-grit silicon carbide paper. The initial $R_{a}$ roughness average value was $6.35 \mathrm{~nm}\left(\mathrm{R}_{\mathrm{a}}\right)$ with a standard deviation of 0.15 , after 10 measurements. Figure 1 shows two 3D profiles of the initial roughness obtained using an AFM (Microscope diMultimode V, Vecco, Controller di Nanoscope V) on random locations of the specimen surface. The projected surface areas were $10 \times 10 \mu \mathrm{m}^{2}$ and $5 \times 5 \mathrm{~m}^{2}$, respectively.

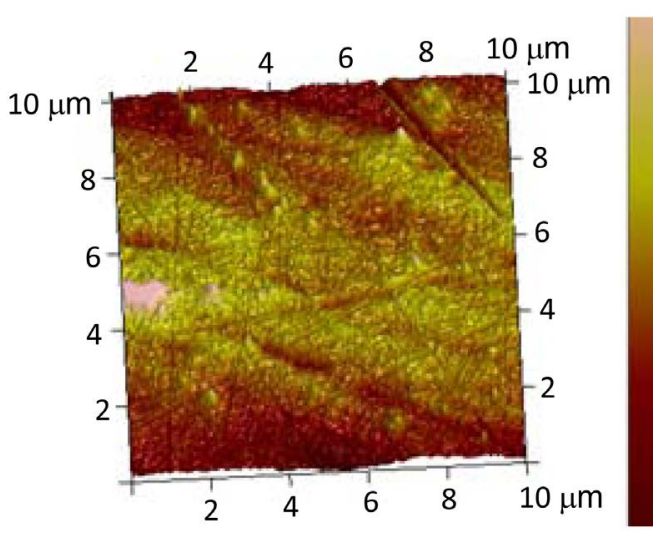

(a)

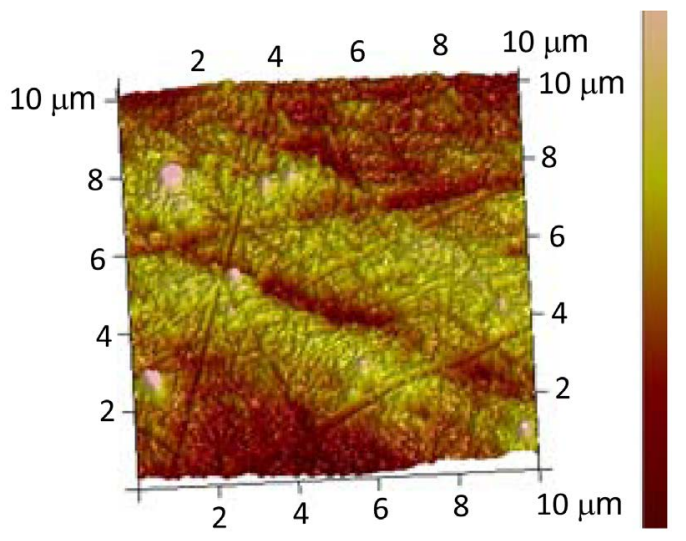

(b)

Figure 1. 3D roughness profiles, (a) $R_{a}=10.4 \mathrm{~nm}$; (b) $R_{a}=6.35 \mathrm{~nm}$. 
Figure 2(a) and Figure 2(b) shows a micrograph of the specimen before erosion tests with different magnifications. The EDS analysis was performed to obtain the chemical composition of the tested material and the results presented the following elements, carbon (C) $0.023 \mathrm{wt} \%$, silicon (Si) $0.80 \mathrm{wt} \%$, copper $(\mathrm{Cu}) 0.40 \mathrm{wt} \%$, oxygen (O) 5.94 wt\%, magnesium (Mg) 1.19 wt\% and aluminum (Al) 69.3 wt\%. The Al samples had a Berkovich hardness of 126 with a standard deviation of 3.66 and a Young Modulus of 90 GPa with a standard deviation of 2.33 after 15 measurements. The applied load was $100 \mathrm{mN}$. These results were obtained using a Nano indentation Tester (TTX-NHT, CSM Instruments).

The samples had a rectangular shape with dimensions of $50 \mathrm{~mm} \times 25 \mathrm{~mm}$ and $3 \mathrm{~mm}$ in thickness. The abrasive particles used were aluminum oxide (alumina) with an angular shape as shown in Figure 3(a) and Figure 3(b). The chemical composition of the abrasive particles presented elements such as oxygen (O) $10.31 \mathrm{wt} \%$, fluorine (F) 4.48 wt\%, aluminum (Al) 22.33 wt\%, silicon (Si) 3.47 wt\%, chromium (Cr) 9.63 wt\%, iron (Fe) $45.11 \mathrm{wt} \%$ and nickel (Ni) $4.67 \mathrm{wt} \%$. Particle size distribution was obtained using an Analysette 28 image sizer. The particle size grain was between 300 and $400 \mu \mathrm{m}$ (Figure 3(c)). Most particles were found in this particular range. The hardness and density of the abrasive particle is $1800 \mathrm{HV}$ and $3.99 \mathrm{~g} / \mathrm{cm}^{3}$ [8].

\subsection{Test Procedure}

The erosion tests were performed by using a rig, which is based on that in the ASTM G76-95 [9]. The schematic diagram of the rig developed is presented in Figure 4. In this rig, the abrasive particles are accelerated from a nozzle by using a compressed air stream that caused them to impact the surface of the material. The average particle velocity was measured with an opto-electronic flight-timer similar to that described by Kosel and Anand [10]. This system offers the possibility to measure the particle velocity in an accurate mode and the design does not request high costs.

The material was eroded for 20 min although each sample was removed every 2 min to determine the mass loss. The impact angles used for the tests were $30^{\circ}, 45^{\circ}, 60^{\circ}$ and $90^{\circ}$. These angles were selected to evaluate the material at low and high impact angles. A particle velocity of $24 \pm 2 \mathrm{~m} / \mathrm{s}$ and an abrasive flow rate of $63 \pm 0.5$ $\mathrm{g} / \mathrm{min}$ were used to conduct the tests. In all of the tests, the specimens were located $10 \mathrm{~mm}$ from the end of the stainless steel nozzle. The nozzle had the following dimensions: $4.7 \mathrm{~mm}$ internal diameter, $6.3 \mathrm{~mm}$ external diameter and a length of $260 \mathrm{~mm}$. The room temperature was between $35^{\circ} \mathrm{C}$ and $40^{\circ} \mathrm{C}$. The specimens were weighed using an analytical balance (with an accuracy of $\pm 0.0001 \mathrm{~g}$ ) before the start of each test and removed every $2 \mathrm{~min}$, cleaned by using acetone and weighed again to determine the amount of mass loss. Micrographs of the eroded surfaces were obtained using a Scanning Electron Microscope (SEM) Quanta 3D FEG (FEI) to analyze the specimens and to identify the possible wear mechanisms.

\section{Erosion Results}

\subsection{Erosion Damage at $30^{\circ}$}

The erosion damage at $30^{\circ}$ was characterized by high plastic deformation on the surfaces as observed in Figure 5 and Figure 6. In this particular case, micro-cutting and micro-ploughing (grooves on the surface) actions were
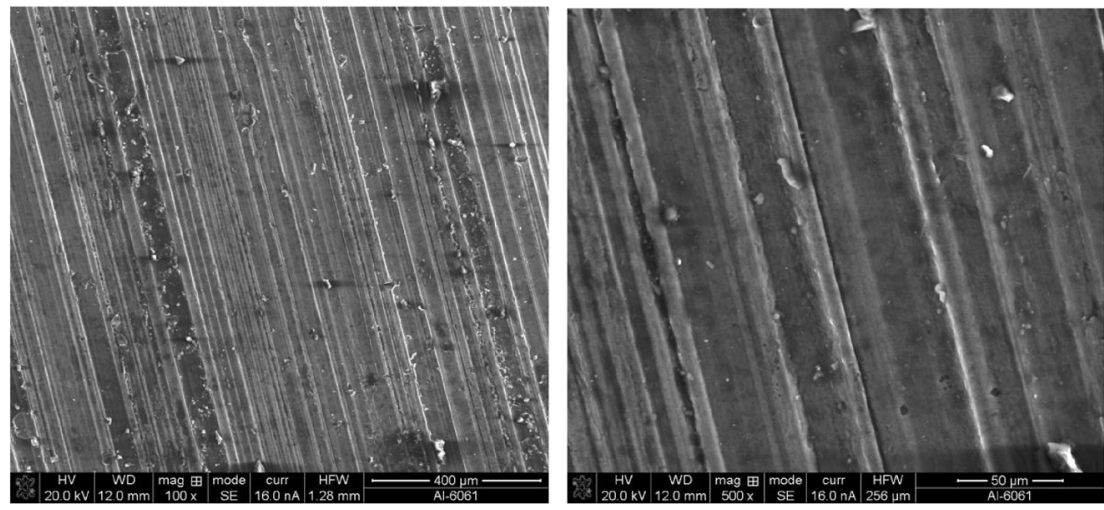

Figure 2. SEM images of AISI 6061-T6, (a) 100×, (b) 500×. 


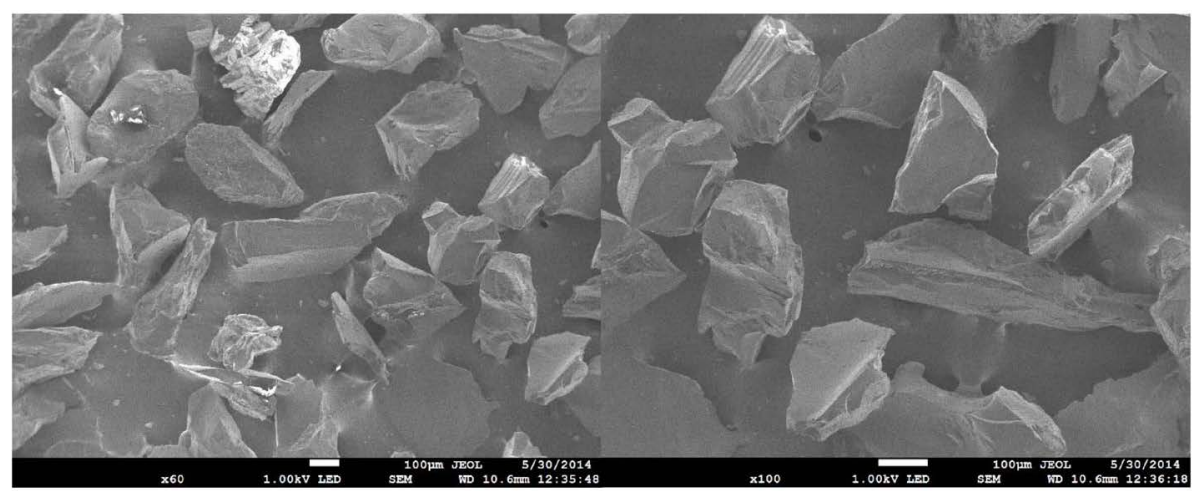

(a)

(b)

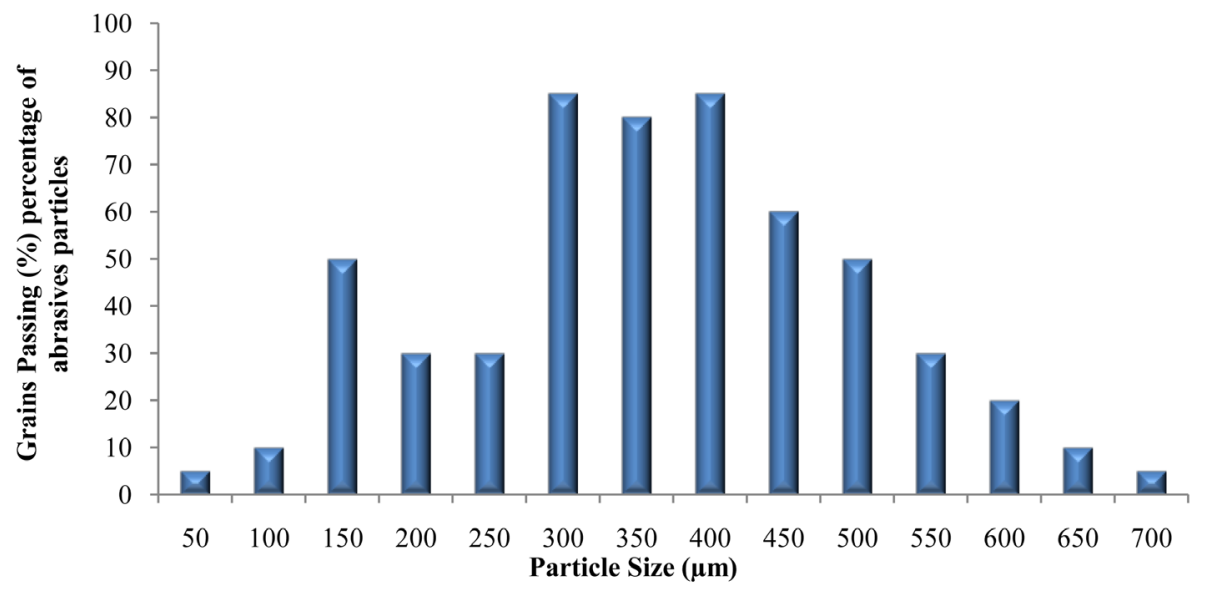

(c)

Figure 3. Abrasive particle, (a) (b) Morphology of alumina; (c) Particle size distribution.

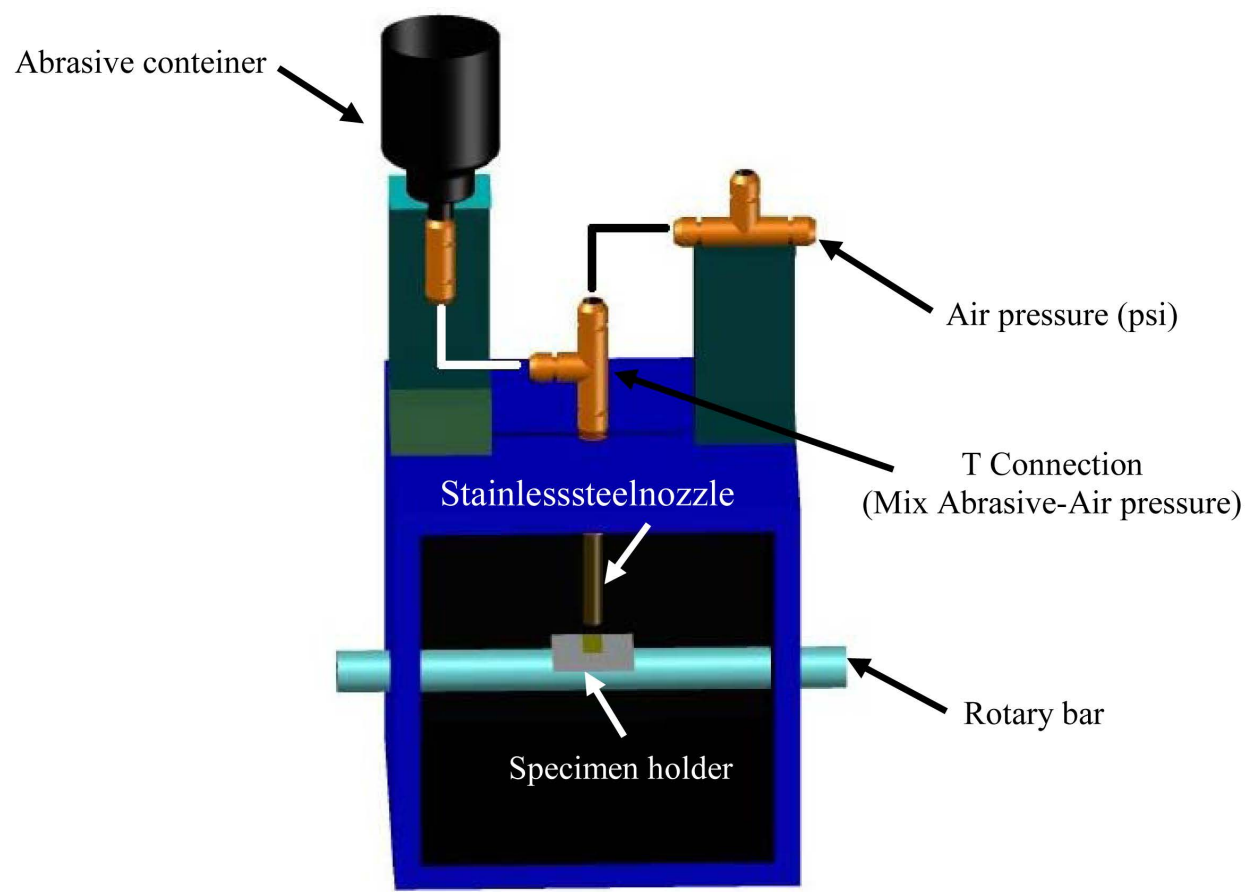

Figure 4. Schematic diagram of erosion rig. 


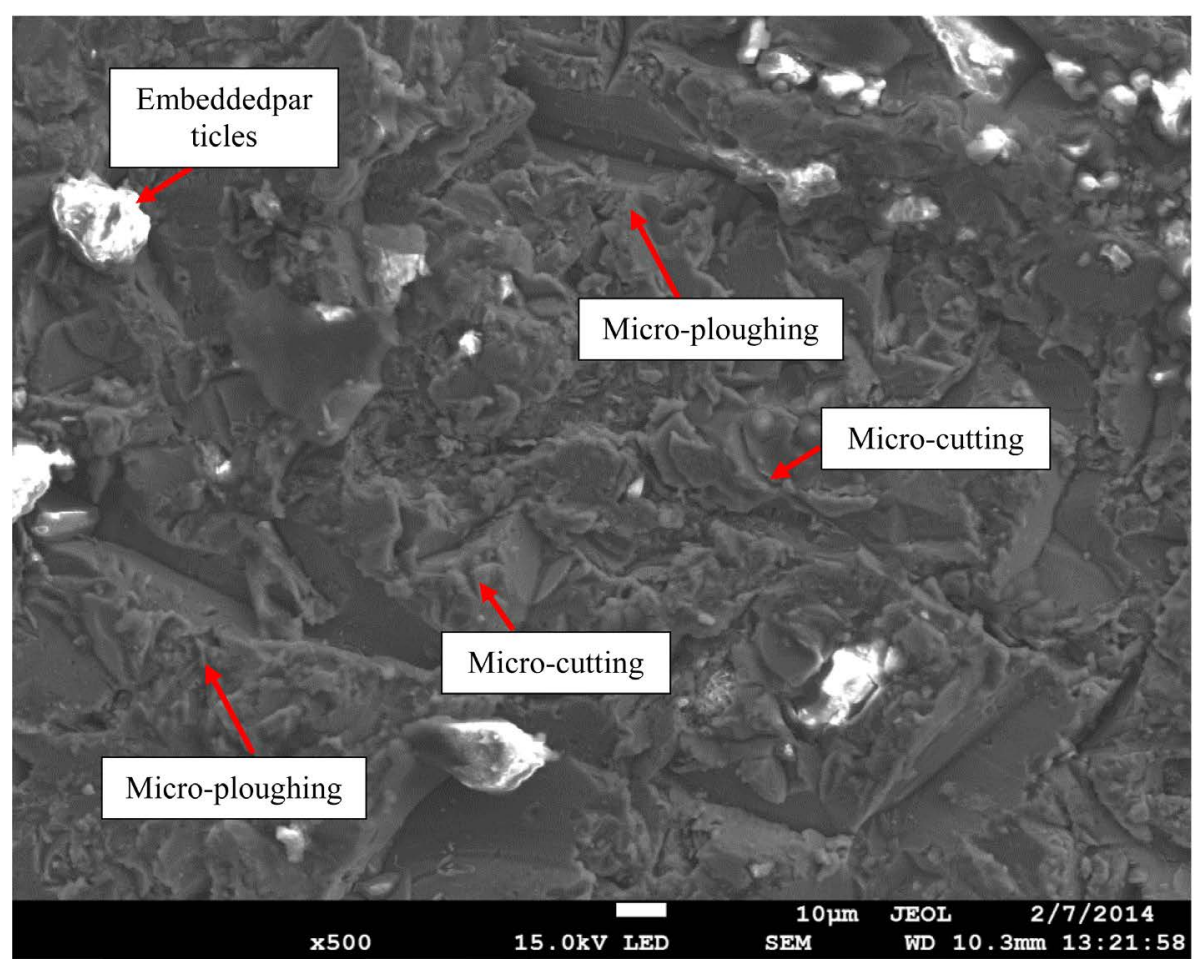

Figure 5. Erosion damage at $30^{\circ}$.

normally seen as observed in other erosion studies with pure aluminum or aluminium alloys [11]-[15]. Some particle fragments were embedded on the surfaces. The alumina particles were probably fragmented during the impact action, due to work-hardening of the aluminum surface inflicted by the permanent impacts and other aspect to consider could be that some particles made contact with embedded fragments and then were fractured. In Figure 6(a) and Figure 6(b), it is possible to observe a particle embedded on the surface with material piled-up in front of it. In addition, Figure 6(c) and d shows EDS spectra in two different points of the damaged surface. Here, the elements that appear in the chemical analysis are carbon $(\mathrm{C})$, oxygen $(\mathrm{O})$ and in the embedded particle a new element can be identified, $\mathrm{Al}$, corresponding to the aluminum oxide. It is possible that a considerable amount of particles could be inserted on the surfaces due to these have high hardness combined with the soft surface of the aluminum alloy.

\subsection{Erosion Damage at $90^{\circ}$}

In respect to the wear damage at $90^{\circ}$, the wear mechanism was high plastic deformationas that observed at $30^{\circ}$. Here, it was possible to identify micro-ploughing and micro-cutting actions, embedded particles and wear debris deposited on the damaged surfaces (see Figures 7(a)-(c)). The wear mechanisms are quite consistent because of the soft structure that this aluminum alloy exhibited. The EDS analysis of Figure 7(d) confirmed the presence of another embedded abrasive particle by the elements found. These were carbon $(\mathrm{C})$, oxygen $(\mathrm{O})$ and aluminum (Al).

\subsection{Volume Loss and Erosion Rates}

The volume loss was obtained dividing the mass loss (g) by the density of AISI $6061\left(2.70 \mathrm{~g} / \mathrm{cm}^{3}\right)$. Two tests were conducted for each incident angle and an average volume loss and standard deviation was obtained. The maximum volume loss $\left(\mathrm{mm}^{3}\right)$ was reached at $30^{\circ}$, where the micro-cutting and micro-ploughing actions caused an increase in the material removal. On the other hand, the least volume loss was seen at $90^{\circ}$. All the results were really close in this particular case. Figure 8 shows the graph of the volume loss against the elapsed time. In all the incident angles, the volume loss was increased in relation to the time.

The total erosion value was also calculated and the results are presented in Figure 9(a) and Figure 9(b). It 


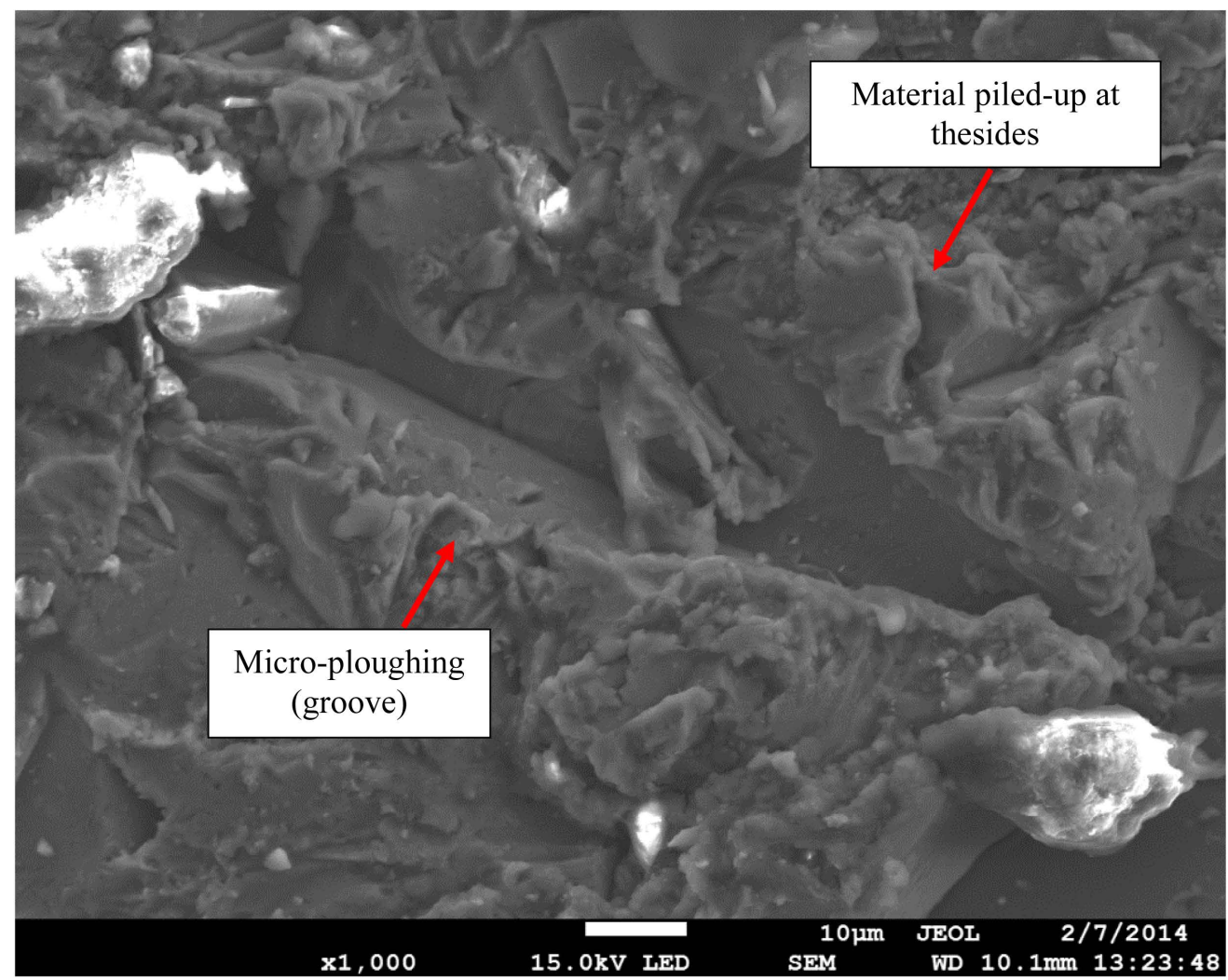

(a)

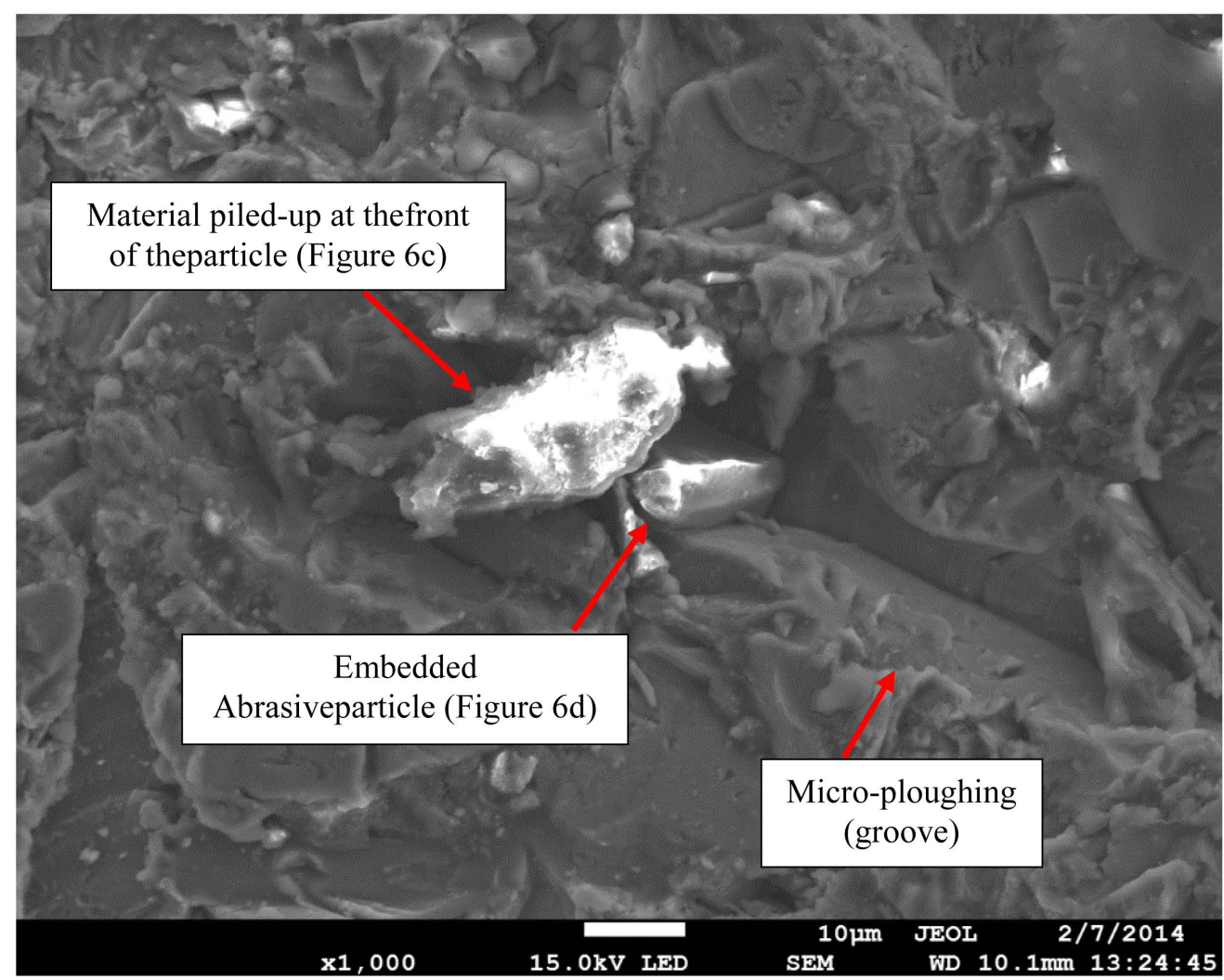

(b) 


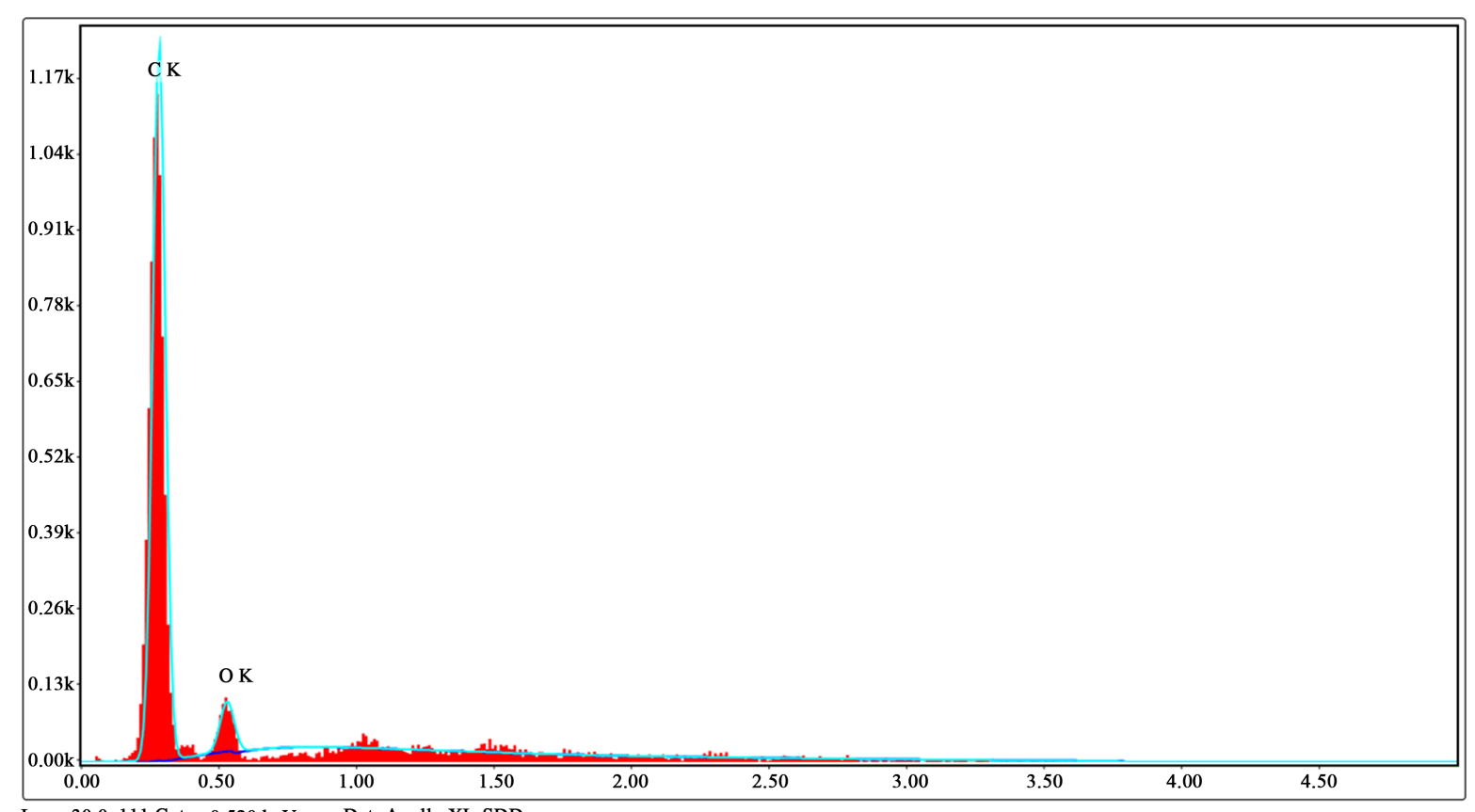

(c)

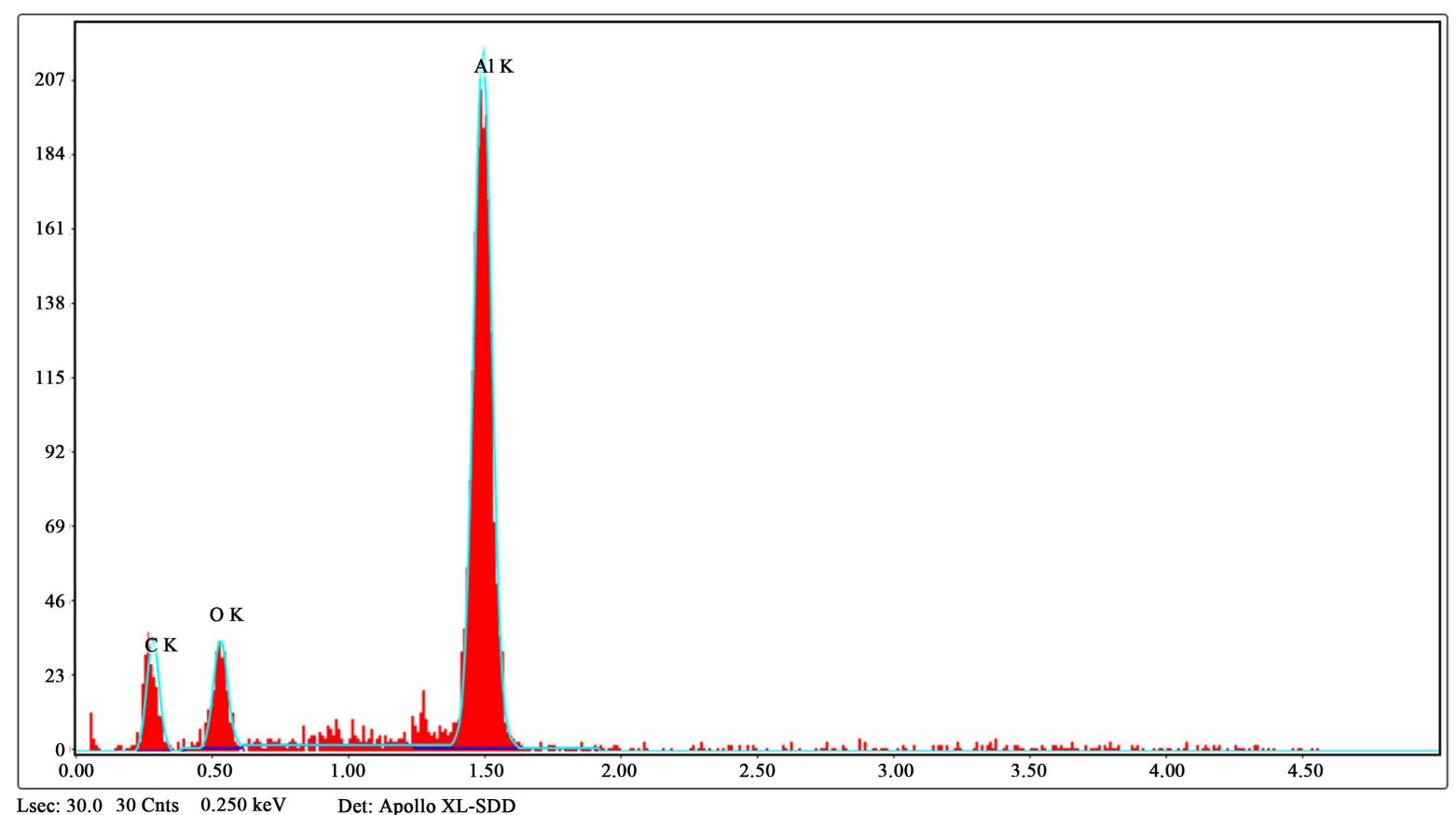

(d)

Figure 6. (a) (b) Erosion at 30; (c) EDS piled-up material in front of the abrasive particle; (d) EDS embedded particle.

was obtained dividing the volume loss $\left(\mathrm{mm}^{3}\right)$ by the total mass of particles ( $\mathrm{g}$ ) that impacted the surface after 20 min as indicated in ASTM G76-95 [9]. As mentioned previously, the maximum erosion rate was at $30^{\circ}$ reducing progresively up to $90^{\circ}$. Here, it is possible to conclude that this material in these particular testing conditions exhibited a ductile type behaviour based on the erosion literature graph presented in different erosion studies [14] [15]. This is a typical behavior of an aluminium alloy because of its high ductility, tenacity and high capacity to be deformed. 


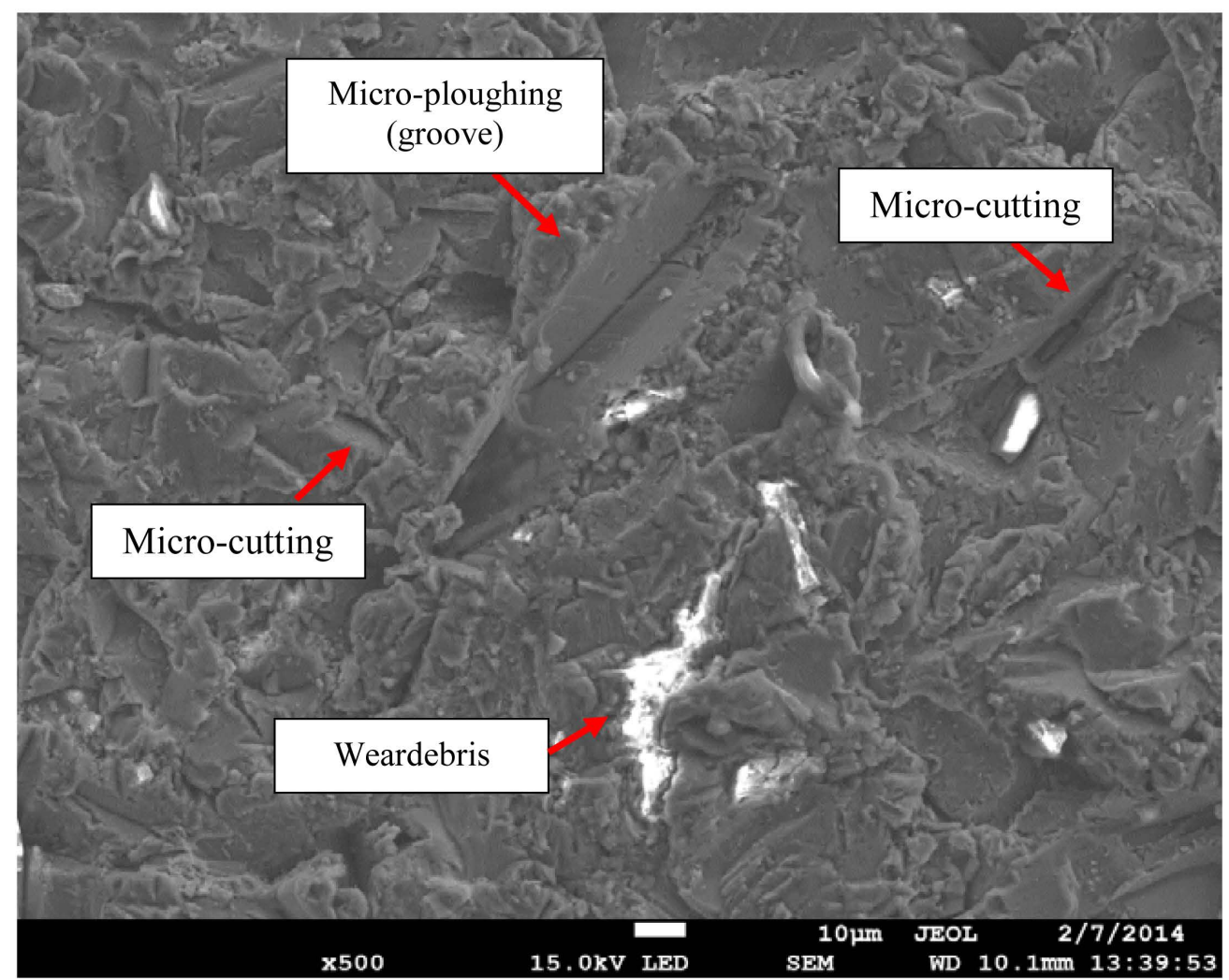

(a)

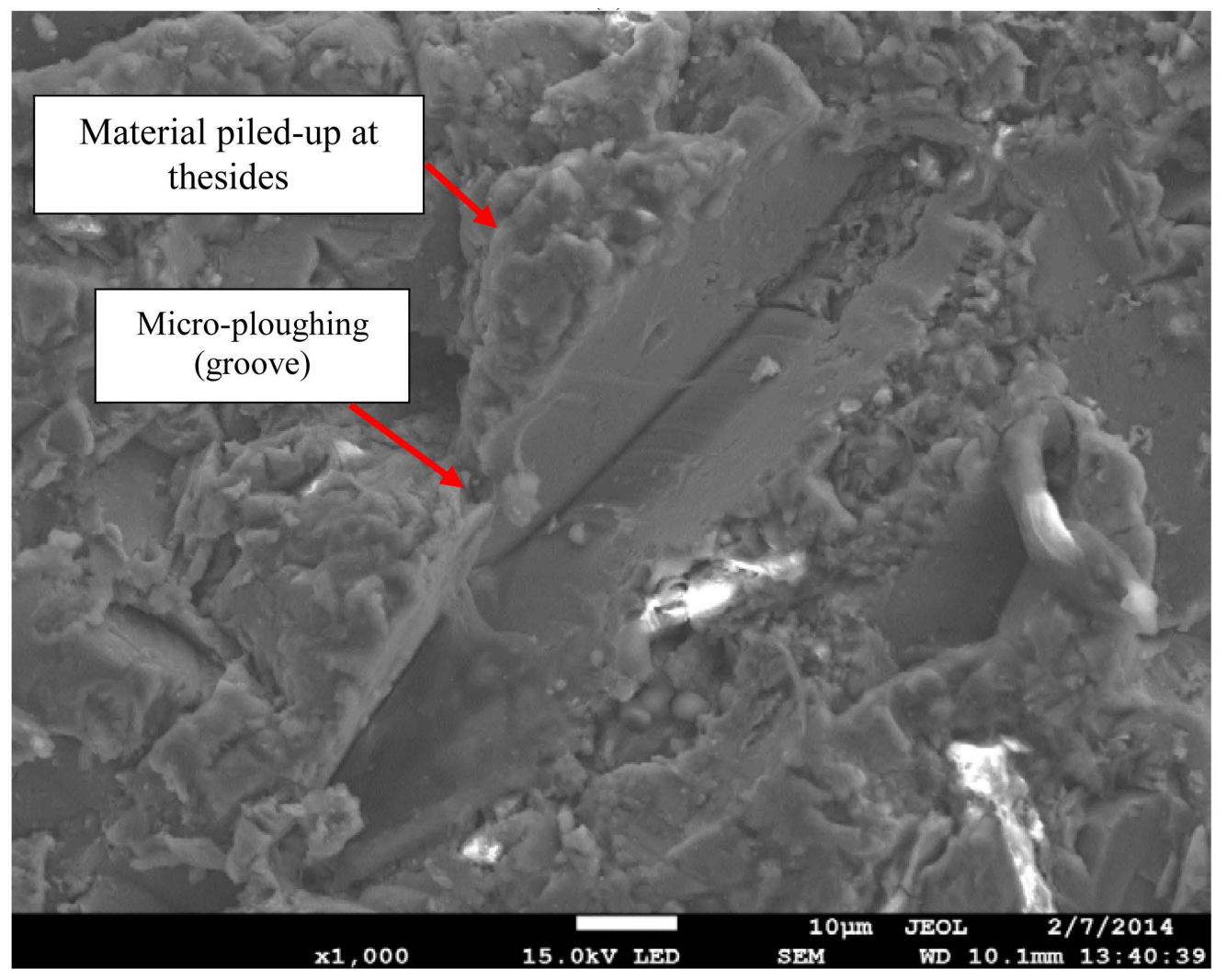

(b) 


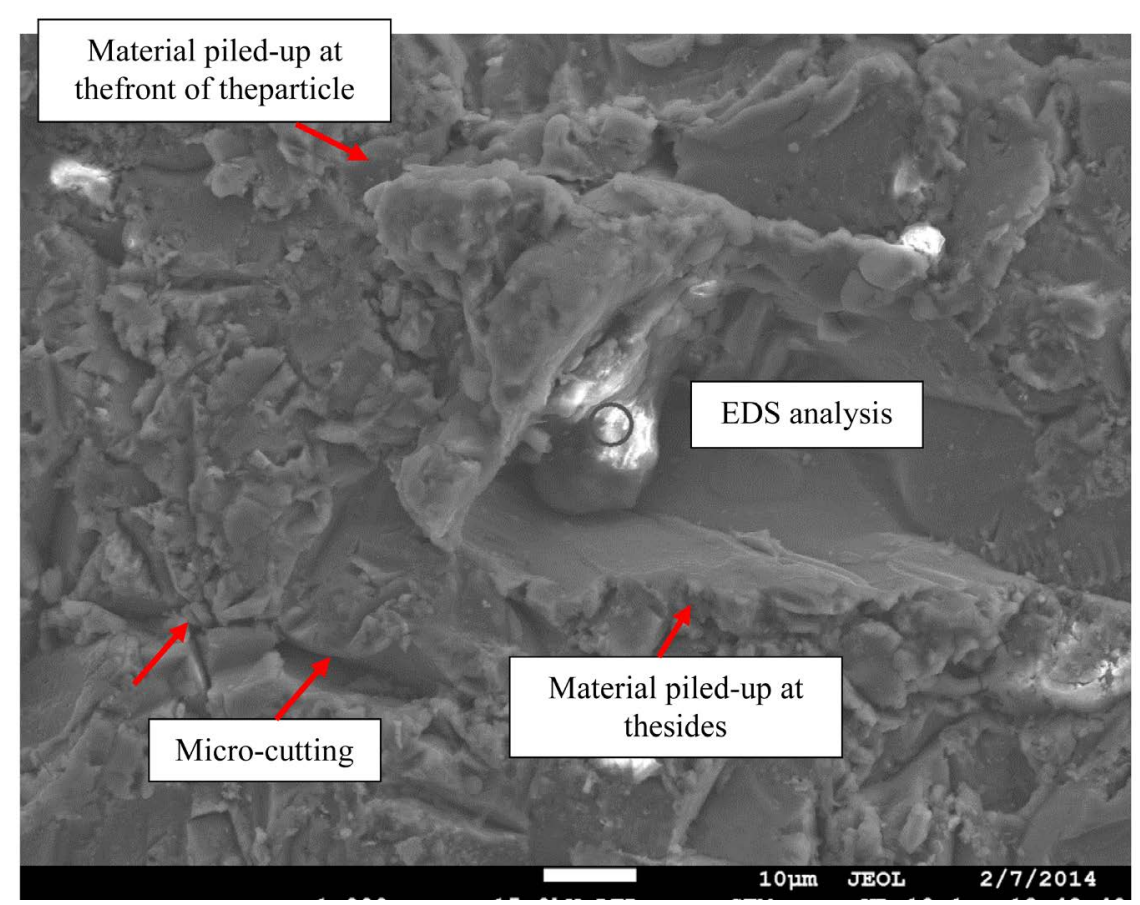

(c)

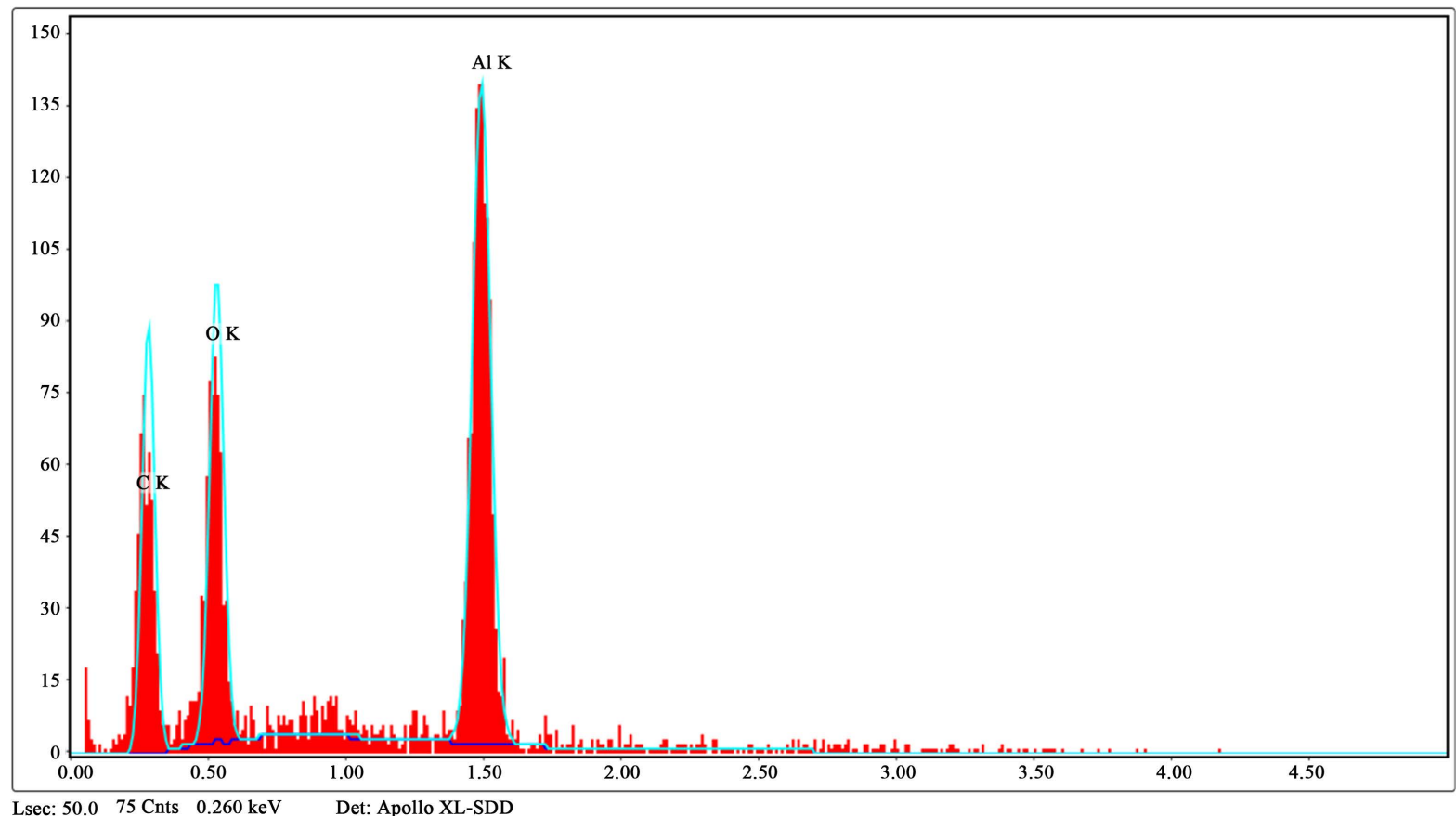

(d)

Figure 7. (a) (b) Erosion at $90^{\circ}$; (c) Different erosion zone at $90^{\circ}$; (d) EDS embedded particle.

\section{Conclusions}

1) The aluminum alloy AISI 6061 showed its maximum erosion rate at $30^{\circ}$. This material exhibited typical ductile type behavior because of its high ductility, tenacity and softness. The lowest erosion rate was exhibited at $90^{\circ}$, where work-hardening could be a factor to decrease the cutting efficiency of the abrasive particles on the surface. 


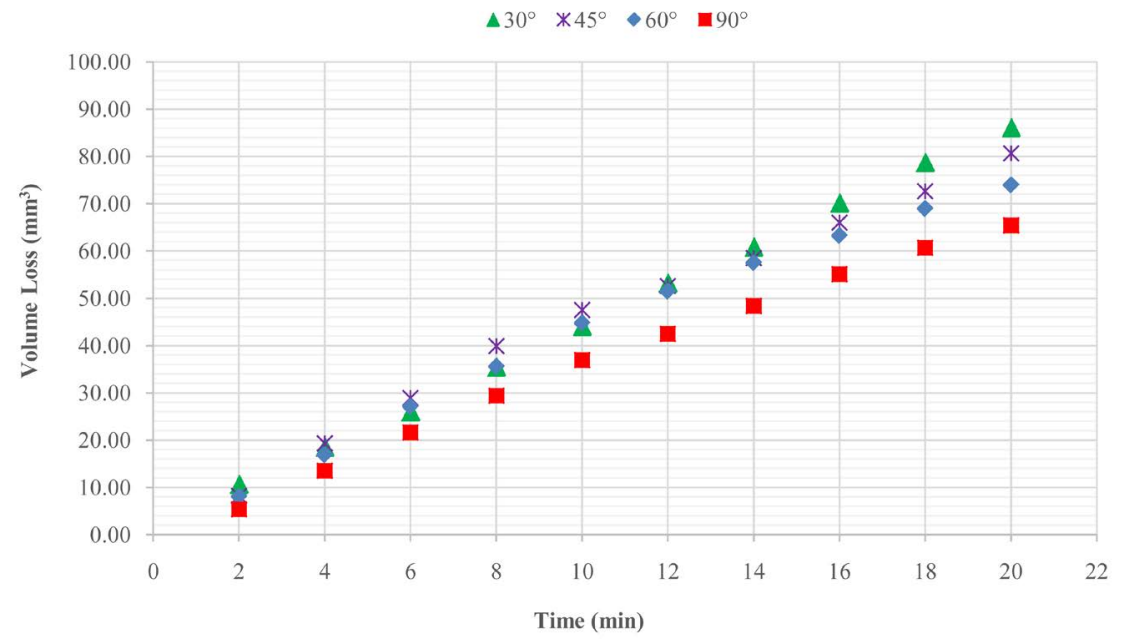

Figure 8. Graph volume loss vs. time.

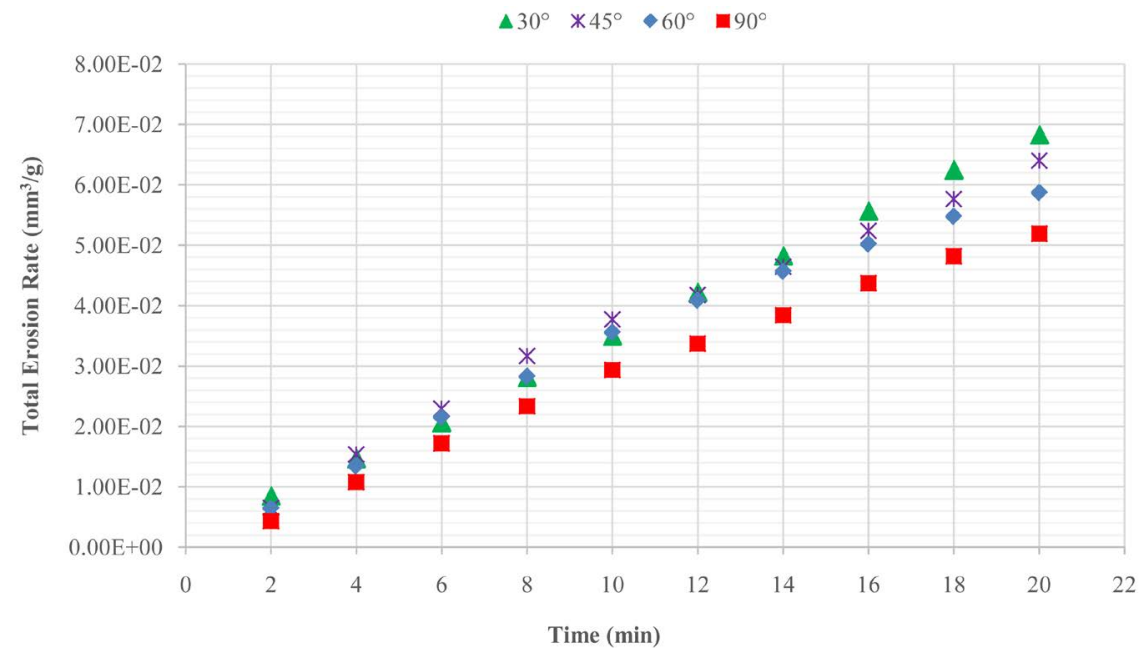

(a)

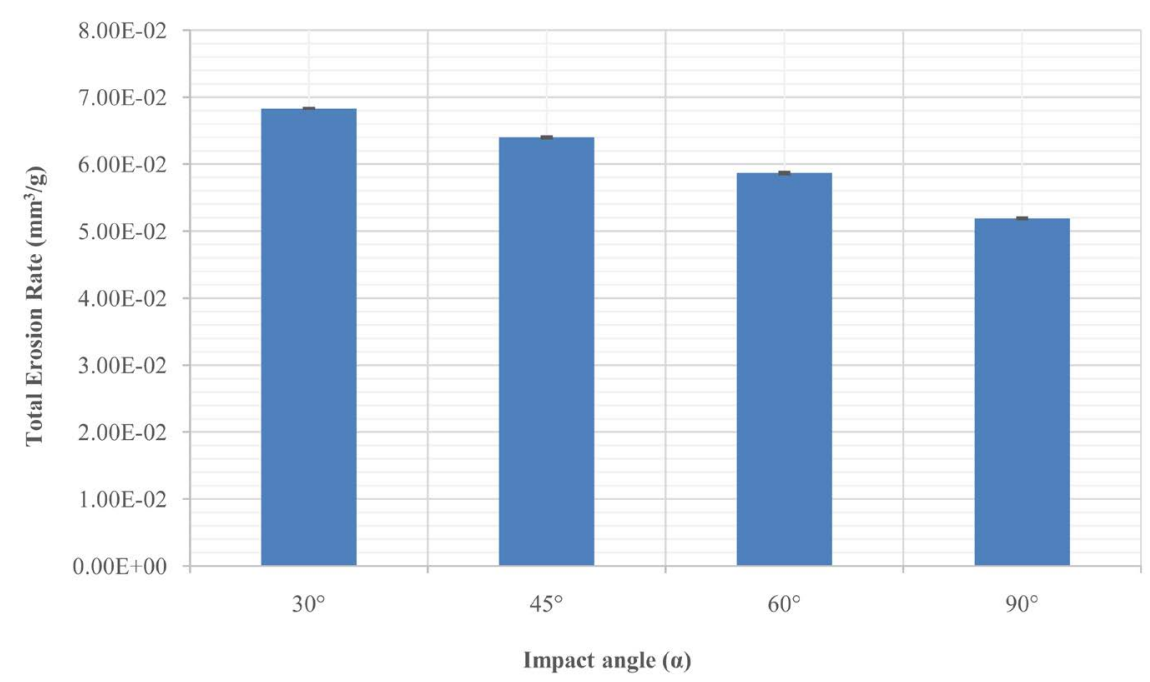

(b)

Figure 9. (a) Total erosion rate vs. time; (b) Total erosion rate vs. impact angle. 
2) SEM images were used to identify the wear mechanisms, which were characterized by high plastic deformation with typical damage modes such as micro-cutting and micro-ploughing actions, several grooves were formed on the surfaces due to the sliding component of the abrasive particles, with material piled-up at the sides and in the front of the particle trajectory. Embedded particles of alumina were also seen on the surfaces.

\section{Acknowledgements}

We recognize the experimental support of CNMN-IPN (Center of Nano science and Micro and Nanotechnology) of the National Polytechnic Institute to complete the present work.

\section{References}

[1] Budinski, K.G. (1995) Erosion of 316 Stainless Steel by Dicalcium Phosphate. Wear, 186-187, 145-149. http://dx.doi.org/10.1016/0043-1648(95)07165-2

[2] Macchini, R., Bradley, M.S.A. and Deng, T. (2013) Influence of Particle Size, Density, Particle Concentration on Bend Erosive Wear in Pneumatic Conveyors. Wear, 303, 21-29. http://dx.doi.org/10.1016/j.wear.2013.02.014

[3] Akbarzadeh, E., Elsaadawy, E., Sherik, A.M., Spelt, J.K. and Papini, M. (2012) The Solid Particle Erosion of 12 Metals Using Magnetite Erodent. Wear, 282-283, 40-51. http://dx.doi.org/10.1016/j.wear.2012.01.021

[4] Azevedo, C.R.F. and Sinátora, A. (2009) Erosion Fatigue of Steam Turbine Blades. Engineering Failure Analysis, 16, 2290-2303. http://dx.doi.org/10.1016/j.engfailanal.2009.03.007

[5] Christman, T. and Shewmon, P.G. (1979) Erosion of a Strong Aluminium Alloy. Wear, 52, 57-70. http://dx.doi.org/10.1016/0043-1648(79)90196-0

[6] Cousens, A.K. and Hutchings, I.M. (1983) A Critical Study of the Erosion of an Aluminium Alloy by Solid Spherical Particles at Normal Impingement. Wear, 88, 335-348. http://dx.doi.org/10.1016/0043-1648(83)90302-2

[7] Veerabhadra-Rao, P., Young, S.G. and Buckley, D.H. (1983) Morphology of Ductile Metals Eroded by a Jet of Spherical Particles Impinging at Normal Incidence. Wear, 85, 223-237. http://dx.doi.org/10.1016/0043-1648(83)90066-2

[8] Feng, Z. and Ball, A. (1999) The Erosion of Four Materials Using Seven Erodents-Towards an Understanding. Wear, 233-235, 674-684. http://dx.doi.org/10.1016/S0043-1648(99)00176-3

[9] (1995) ASTM Standard, G76-95, Standard Practice for Conducting Erosion Tests by Solid Particle Impingement Using Gas Jets. Vol. 0.302, ASTM, Philadelphia, in Annual Book of ASTM Standards.

[10] Kosel, T.H. and Anand, K. (1989) Optoelectronic Velocimeter Development (Technical Report). Technical Information Center, Oak Ridge.

[11] Hutchings, I.M. and Winter, R.E. (1974) Particle Erosion of Ductile Metals: A Mechanism of Material Removal. Wear, 27, 121-128. http://dx.doi.org/10.1016/0043-1648(74)90091-X

[12] Tilly, G.P. (1969) Erosion Caused by Airborne Particles. Wear, 14, 63-79. http://dx.doi.org/10.1016/0043-1648(69)90035-0

[13] Finnie, I. (1960) Erosion of Surfaces by Solid Particles. Wear, 3, 87-103. http://dx.doi.org/10.1016/0043-1648(60)90055-7

[14] Harsha, A.P. and Kumar-Bhaskar, D. (2008) Solid Particle Erosion Behaviour of Ferrous and Non-Ferrous Materials and Correlation of Erosion Data with Erosion Models. Materials and Design, 29, 1745-1754. http://dx.doi.org/10.1016/j.matdes.2008.03.016

[15] Oka, Y.I., Nishimura, M., Nagahashi, K. and Matsumura, M. (2001) Control and Evaluation of Particle Impact Conditions in a Sand Erosion Test Facility. Wear, 250, 736-743. http://dx.doi.org/10.1016/S0043-1648(01)00710-4 